\title{
Developmental Links Between Disobedient Behavior and Social Classroom Relationships in Boys With Psychiatric Disorders in Special Education
}

\author{
L. D. Breeman - P. A. C. van Lier • T. Wubbels • \\ F. C. Verhulst • J. van der Ende - A. Maras • \\ J. A. B. Hopman • N. T. Tick
}

Published online: 12 September 2014

(C) Springer Science+Business Media New York 2014

\begin{abstract}
In mainstream education, positive relationships with teachers and peers have been found to positively influence children's behavioral development. However, high levels of classroom behavior problems may hinder the formation of such positive relationships. Therefore, findings from mainstream education cannot be generalized to special education. The present study investigated the developmental links between disobedience and positive as well as negative relationships with teachers and peers among boys in restrictive special educational settings. At three assessment waves across one school year, teacher-reports of teacher-child closeness and conflict, and peer-reports of peer acceptance, rejection and disobedience were collected among 340 boys (mean age $=10.1$ years, $\mathrm{SD}=1.58$, range $=5-13$ ) with psychiatric disorders receiving special education. Autoregressive cross-lagged models were fitted to explore the nature of these developmental links. The
\end{abstract}

Electronic supplementary material The online version of this article (doi:10.1007/s10802-014-9935-0) contains supplementary material, which is available to authorized users.

L. D. Breeman $(\bowtie) \cdot$ A. Maras · J. A. B. Hopman • N. T. Tick Yulius Mental Health, Yulius Academy, Mathenesserlaan 202, 3014HH Rotterdam, The Netherlands

e-mail: L.Breeman@yulius.nl

L. D. Breeman · F. C. Verhulst • J. van der Ende · J. A. B. Hopman •

N. T. Tick

Department of Child and Adolescent Psychiatry/Psychology, Erasmus MC - Sophia Children's Hospital, PO Box 2060,

3000CB Rotterdam, The Netherlands

P. A. C. van Lier

Department of Developmental Psychology, VU University

Amsterdam, Van der Boechorststraat 1, 1081BT Amsterdam,

The Netherlands

T. Wubbels

Faculty of Social and Behavioral Sciences, Utrecht University, PO Box 80140, 3508TC Utrecht, The Netherlands impact of boys' age was examined using multiple group analyses. Findings supported the importance of teacher-child conflict, but not closeness, and positive and negative peer relationships for the development of boys' disobedience, with a stronger effect of negative than positive relationships. However, teacher-child and peer relationships were not longitudinally related and the effect of boys' age was minimal. This study extends prior research by suggesting that, despite differences in educational setting and severity of behavior problems between children in mainstream and special education, reducing negative classroom interactional patterns is most important in preventing the development of problematic classroom behavior in boys with severe social-emotional and behavioral difficulties.

Keywords Behavior problems · Teacher-child relationship · Peer relations $\cdot$ Special education $\cdot$ EBD

In mainstream education, teacher-child and peer relationships have consistently been identified as key factors for the social and behavioral development in children (Ladd 1990; Sabol and Pianta 2012). However, 1-5 \% of children in western nations such as in the U.S. or in European countries are placed in segregated settings for special education (Meijer 2003; U.S. Department of Education 2009). One reason why children are placed in such settings is because of their special educational needs related to disabilities associated with severe socialemotional or behavioral disturbances (Stoutjesdijk and Scholte 2009; U.S. Department of Education 2009). The criteria for including children with psychological disabilities in self-contained special education classrooms in the Netherlands stipulate that children must have at least one psychiatric diagnosis, and must show severe behavior problems, at school and at home, that together limit their participation in mainstream education (Ministerie OCW 2003). The specific psychiatric problems of children in special 
education - mainly boys diagnosed with attention deficit hyperactivity disorder (ADHD), autism spectrum disorder (ASD) or disruptive behavior disorder (DBD; Stoutjesdijk and Scholte 2009) - may lead them to engage in disobedient behavior such as verbal disruptions and inappropriate behavior. This behavior not only disturbs the educational process, but may also hinder the development of their social relationships with teachers and peers (Bellini et al. 2007; Rich et al. 2009). Therefore, we cannot assume that findings from mainstream education on the links between classroom relationships and children's behavioral development can be generalized to boys in special education. The present study contributes to knowledge on developmental links between disobedience and classroom relationships of boys with psychiatric disorders in segregated settings for special education.

\section{Links Between Disobedient Behavior and Social Classroom Relationships}

Although it has been widely acknowledged that positive social relationships with teachers and peers are important for children's behavioral development, the theoretical and empirical evidence is less clear when it comes to the direction of effects. From an attachment perspective, it can be assumed that children develop internal working models of the social world and themselves, based on their relationships with adult caregivers, and apply these attachment-related expectations to future social interactions (Bowlby, 1969/1982). Children with secure attachments may therefore develop more positive social relationships with their teachers than children who are insecurely attached (Verschueren and Koomen 2012). Consistent with this theory, empirical work indicates that the more securely attached children are to their teacher, the less externalizing and aggressive problems they will exhibit (Baker 2006; Hughes et al. 1999), which suggests that teacher-child closeness reduces children's behavior problems. However, from the teacher's perspective, behavior problems such as disobedience and provoking confrontations represent a major challenge (Hamre et al. 2008). As might be expected, studies in mainstream education have shown that children's externalizing behavior negatively influences teacher-child closeness and conflict, which in turn increases children's externalizing behavior (De Laet et al. 2014; Doumen et al. 2008; Mercer and DeRosier 2008). These findings suggest that children with behavior problems may get caught in a vicious cycle of negative interactions.

Besides teachers, peers also impact children's behavior. Children's friendships with peers differ from teacher-child relationships in the sense that peers provide a social mirror that is used to validate a child's developing self-image (Gifford-Smith and Brownell 2003). Empirical studies found that poor appraisal by peers predict increases in disobedient and aggressive behavior, even after controlling for both the reverse effect of children's behavior on peer rejection and prior behavior problems (Leflot et al. 2011; Mercer and DeRosier 2008; Sturaro et al. 2011). It has been suggested that such behavioral reactions of children to poor appraisal by their peers are because children perceive the school environment as non-supportive (Ladd 1990), or because of social cognitive biases such that rejected children are more likely to perceive ambiguous peer behavior as hostile and therefore may show more behavior problems (Gifford-Smith and Brownell 2003). However, there is also evidence of an effect in the opposite direction: the behavior problems of children predict poor appraisal and rejection by classmates (Leflot et al. 2011; Mercer and DeRosier 2008; Sturaro et al. 2011). This is likely because children's disobedience cause classroom disruptions which may affect all classmates (Carrel and Hoekstra 2010) and therefore classroom climate in general. Alternatively, the children showing disobedience may be regarded by peers as less mature (Ladd 1990) or more social naive (Rich et al. 2009) which may lead to less social acceptance.

\section{Indirect Effects on Disobedience: Links between Social Classroom Relationships}

From a developmental systems perspective, children's classroom behavior and their classroom relationships with teachers and peers are all interrelated (Pianta et al. 2003). Therefore, when examining developmental links between children's behavior and social relationships in the classroom, it is important to include both teacher-child and peer relationships to disentangle their effects on children's behavioral development, and also take into account the links between teacher-child and peer relationships. Empirical studies have shown that teacher-child and peer-child relationships can reinforce one another (Hughes and Chen 2011; De Laet et al. 2014; Leflot et al. 2011; Mercer and DeRosier 2008). A possible explanation for the impact of the teacher-child on peer relationships comes from social referencing theory (Hughes et al. 2001), which presumes that the teacher serves as a social referent for children, thereby allowing classmates to make inferences about children's likability based on their observations of teacherchild interactions. It has indeed been found that receiving more teacher support increased the likelihood of later higher appraisal by peers (Hughes and Chen 2011; De Laet et al. 2014; Mercer and DeRosier 2008). However, this result was not confirmed in a study by Leflot et al. (2011). Interestingly, effects of peers on teachers are shown to be stronger and more consistent than the reverse effect of teachers on peers (Mercer and DeRosier 2008; De Laet et al. 2014). More consistent findings showed that peer rejection reduced the support children received from teachers 2 to 3 years later (De Laet et al. 
2014; Hughes and Chen 2011; Leflot et al. 2011; Mercer and DeRosier 2008). It thus appears that teachers also make inferences about a child based on the child's interactions with peers, because positive peer interactions may lead to more cooperation and engagement in the classroom resulting in teachers increasingly preferring this child (Hughes and Chen 2011; Leflot et al. 2011). Therefore, in the present study, we will examine the developmental links between teacher-child and peer relationships.

\section{Advancing Current Knowledge: Some Conceptual and Methodological Considerations}

Several conceptual and methodological considerations need to be taken into account to advance and contribute to current knowledge on classroom processes. First, prospective instead of cross-sectional research is needed to provide evidence on the direction of effects between classroom relationships and disobedience. To establish whether these processes truly impact one another over time, developmental links should be adjusted for the impact of both stability paths and crosssectional correlations. With some positive exceptions (De Laet et al. 2014; Doumen et al. 2008; Leflot et al. 2011; Mercer and DeRosier 2008; Sturaro et al. 2011; Zhang and Sun 2011), such analyses were, until recently, rarely common practice, leading to an overestimation of developmental effects. Therefore, our study will employ autoregressive crosslagged modeling to establish the unique contributions of children's disobedience, teacher-child and peer relationships on their future social and behavioral development.

Second, much research has been directed on the links between classroom relationships and children's behavioral development in children attending mainstream education. Far less is known about classroom relationships and behavior in clinical samples of children with psychiatric disorders placed in special education, while especially these children are at risk for experiencing low psychosocial, emotional, and behavioral adjustment after leaving school (Heijmens Visser et al. 2003). It is however premature to assume that developmental links found in mainstream education can be generalized to children with severe social-emotional and behavioral difficulties, such as children with ADHD, ASD or DBD in special education. For example, it has been found that children with severe emotional disturbances experience less affiliation and more dissatisfaction with teachers (Murray and Greenberg 2001), and encounter more negative and less positive peer interactions at school (Little and Kobak 2003) than children without disabilities. Likewise, children with behavior disorders collaborate less with their teachers (Toste et al. 2012) and children with ADHD and behavior problems experience more peer rejection (Hinshaw and Melnick 1995) than children without disabilities. Similarly, social difficulties such as bullying and having less social support are also found among children with autism (Humphrey and Symes 2010; Russel et al. 2012). These troublesome social experiences among children with ADHD, ASD and DBD may be problematic because positive social relationships may facilitate children's social and behavioral development whereas negative social relationships may profoundly promote maladjustment (see for a review: Sabol and Pianta 2012). Supporting this assumption, research has shown that especially children with higher levels of behavior problems in mainstream education benefit from positive classroom relationships (Baker 2006; Silver et al. 2005). Also, the impact of classroom relationships may be even stronger for children in special education because class size is usually much smaller than in mainstream education, which may result in more individual teacherchild interactions and individualized attention (Little and Kobak 2003). However, it is also possible that clinical samples of children with psychiatric disorders in special education are impacted less by social relationships than children with high levels of behavior problems in mainstream education. Children in special education generally have more profound behavior problems, both at school as well as at home, which may lead to a cascade of negative classroom interactions. The severity and complexity of children's problems in special education may therefore hamper the formation of positive relationships with teachers and peers, and thereby limit the extent to which these children may benefit from positive aspects of social relationships. It is thus questionable to what extent positive and negative aspects of social relationships with teachers and peers actually affect these children's behavioral development. We therefore examine the links between disobedience and classroom relationships among this clinical population in special education.

Third, studies may want to take into account the impact of children's age as the strength of the links between classroom relationships and children's behavior may depend on age. Social referencing theory (Hughes et al. 2001) states that children use the teacher as a social referent for a child's likability. However, this may apply more to younger than to older children, as younger children are more susceptible to teacher expectancies than older children (Kuklinski and Weinstein 2001). As children grow older, they tend to rely more on their peers and increasingly use their peers as a reference for the development of their own identity (GiffordSmith and Brownell 2003). Also, behavior problems may have less impact on the social classroom relationships of younger than older children as this behavior may be more normative and adaptive for younger children (Gifford-Smith and Brownell 2003). As it is possible that children's age moderates the strength of the links between children's disobedience and social relationships, age-effects are examined in the current study. 
Fourth, the relative influence of negative versus positive aspects of social relationships may also differently impact behavioral development. In a review by Baumeister et al. (2001), it is argued that from an evolutionary perspective, negative traits and relationships have a stronger impact than positive traits and relationships, as individuals who attune to bad things are more likely to survive and pass on their genes. In their review, they consistently show stronger, more pervasive, and longer lasting psychological effects of negative than of positive aspects of relationships, which implicates that children's disobedience may be more dependent on their negative than their positive social relationships. Indeed, a study by Ladd et al. (1999) shows that teacher-child conflict and peer rejection were more important predictors of children's classroom adjustment than teacher-child closeness and peer acceptance. Also, a study by Zhang and Sun (2011) shows that teacher-child conflict was more strongly related to children's externalizing behavior than teacher-child closeness. For that reason, we will examine two models: a positive relationships model including teacher-child closeness and peer acceptance, and a negative relationships model including teacher-child conflict and peer rejection.

\section{The Present Study}

This study extends prior research by examining developmental links between positive and negative aspects of teacherchild and peer relationships and disobedience, in a clinical sample of 340 boys with psychiatric disorders in special education, who were followed across one school year. Note that as relatively few girls with psychiatric disorders receive special education in Dutch segregated settings (Stoutjesdijk and Scholte 2009), we only included boys in our study. Specifically, we aimed to study (1) the nature of the developmental links between boy's disobedience and their classroom relationships, (2) whether developmental links between teacher-child and peer relationships indirectly impact boys' disobedience, (3) whether the developmental links between boy's disobedience and classroom relationships differ as a function of boys' age, and (4) whether negative aspects of social relationships with teachers and peers (i.e. teacher-child conflict and peer rejection) affect these boys' behavioral development more than positive aspects (i.e. teacher-child closeness and peer acceptance). Based on theoretical research and related empirical work in mainstream education, we first expect to find the previously reported developmental links between disobedience and classroom relationships to be also present in boys in special education. Second, we expect to find developmental links between classroom relationships. Third, we expect to find the teacher-child relationship's impact on disobedience to be stronger for younger than for older boys and the impact of peer relationships to be stronger for older than for younger boys. Fourth, we expect a stronger impact of negative than positive relationships on disobedience.

\section{Method}

Procedure and Participants

According to procedures approved by the Dutch Medical Ethics Committee for Mental Health Care (METiGG), written informed consent to participate in this study was obtained from school management (school participation), teachers (teacher participation), and parents (child participation). Children had been informed on the study's purpose and voluntary participation through leaflets. Eleven segregated schools for special education, including 58 classes for children with psychiatric disorders, agreed to participate in the study. Within the first 6 weeks of the school year, the principals of three of the schools decided that a total of six classes were not able to participate in the study due to problems present in these classes, such as teachers resigning or experiencing burnout problems. Over the school year, 70 teachers gave written informed consent to participate in the study and to complete questionnaires about their students. These teachers were considered the main teacher, as they taught these boys most days of the week. These teachers' mean age was 38.1 years (range $19-62$ years), $81.4 \%$ were female, $85.7 \%$ had a bachelor's degree, and their mean years of experience in special and mainstream education was 13.1 (range $1-48$ years). The mean number of children in each class was 9.8 . All boys ( $87 \%$ of the children in these classes) in grades 1-6 who were in a participating class at the start of the study were eligible for inclusion $(n=424)$. For $85 \%$ of these boys $(n=362)$, parental informed consent was obtained. During the school year, 22 boys dropped out of the study because they were transferred to other schools, resulting in a final study sample of 340 boys.

The boys' mean age in the final sample was 10.1 years (range 5-13 years, $\mathrm{SD}=1.58$ ) and they had a mean IQ of 88.9 (range 56-143, $\mathrm{SD}=15.38$ ). We obtained information on psychiatric diagnoses from school medical files. The certified mental health professionals who had diagnosed the children at the time of placement in special education were not affiliated with our study. All boys had at least one psychiatric disorder and $48 \%$ of the boys had comorbid psychiatric disorders. Most common psychiatric disorders were ASD (46.2 \%), ADHD (39.4\%), DBD (29.4\%), anxiety disorder $(5.3 \%)$ and mood disorder (3.8 \%). Most common comorbid disorders were ASD with ADHD, and ADHD with DBD (both $13.8 \%$ ). Parents' nationality at birth was used to asses boys' ethnicity (Dutch: $46.8 \%$, ethnic minority: $14.1 \%$, unknown: $39.1 \%$ ). To provide an indication of boys' SES, their parents' occupational level was used (low: $27.4 \%$, middle: $23.8 \%$, high: $11.5 \%$, unknown: $37.4 \%$ ). Boys lost to 
follow-up did not differ from participating boys with regard to child characteristics $\left(M_{\mathrm{age}}=9.7\right.$ years, $\mathrm{SD}=1.93, p=0.30$; $\left.M_{\mathrm{IQ}}=90.2, \mathrm{SD}=11.31, p=0.72\right)$ or on baseline assessments of disobedience $(M=0.22, \mathrm{SD}=0.21, p=0.97)$, peer acceptance $(M=0.34, \mathrm{SD}=0.20, p=0.50)$, and rejection $(M=0.27$, $\mathrm{SD}=0.24, p=0.25)$. However, they had marginally significant lower scores on teacher-child closeness $(M=3.50, \mathrm{SD}=0.77$, $p=0.08)$ and marginally significant higher scores on teacherchild conflict $(M=2.81, \mathrm{SD}=0.98, p=0.07)$.

This study was executed as part of a randomized controlled trial. Half of the study sample received a preventive intervention program, the Good Behavior Game, aimed at improving children's behavior problems. Results showed that at the end the school year, the intervention had not affected the boys' teacher-child or peer relationships. The intervention had a small effect (Cohen's $d=0.14$ ) on boys' behavior problems: the disruptive behavior of boys in the intervention group remained relatively stable, while the level of disruptive behavior in the control group increased somewhat over the school year (Breeman et al., submitted). Given the limited impact of the intervention, we included all boys in the current study. To correct for a possible effect of the intervention on the developmental links between disobedient behavior and social classroom relationships, we added study condition as a covariate in the analyses (control group $=0$; intervention group $=1$ ).

\section{Measures}

There were three assessment waves: at the beginning, halfway through, and at the end of the school year.

Disobedient Behavior Disobedient behavior was evaluated by means of peer nominations (Coie and Dodge 1988) using the question "which child disobeys the teacher?". An unlimited number of children could be nominated. To account for variability in classroom size, scores were adjusted by dividing each individual child's total number of nominations by the number of participating children in the class minus one (selfnominations were not allowed). This meant that scores for disobedient behavior could range between 0 and +1 . Over the three measurement waves, the mean number of children providing peer nomination data in relation to each classmate ranged between 9.0 and 9.6 (range SD: 2.4-2.5; median number of nominating classmates: 9 ). In addition, over the three measurement waves, between 85 and $94 \%$ of the children received nominations from 7 classmates or more. Although there is not much empirical research on the reliability of peer nominations, it has been found that a minimum participation rate of $40-85 \%$ is needed to yield reliable peer nominations scores, depending on class size and specific item (because there is more classroom agreement on children's behavior than on affective reactions such as peer relationships; Marks et al. 2013). As the mean participation rate of children providing peer nominations in our sample ranged between 85 and $92 \%$ across the three measurement waves, the participation rate was considered large enough to obtain reliable peer nominations data. In addition, peer nominations are considered a valid way of assessing children's classroom behavior (Diamantopoulou et al. 2005).

Teacher-Child Relationship Teacher reports of the teacherchild relationship were collected using the Closeness (11 items, Cronbach's alpha 0.88-0.90) and Conflict subscales (11 items, Cronbach's alpha 0.91-0.93) of the Student Teacher Relationship Scale (STRS; Koomen et al. 2007; Pianta 2001). Teachers rated items such as "I share an affectionate, warm relationship with this child", and "This child and I always seem to be struggling with each other" on a five-point scale ranging from 1 (definitely does not apply) to five (definitely applies). Good convergent validity of the STRS has been established (Doumen et al. 2009). However, as recent findings showed that measurement invariance of the STRS might not completely hold across age (Koomen et al. 2012), we additionally tested this in our sample. Results of these tests can be found in the online supplement. In short we found that invariance of both the closeness and conflict scale was supported across age in our sample.

Peer Relationships Peer nominations of 'liked most' and 'liked least' children in class were used to assess peer acceptance and rejection. Similar to disobedience, scores were corrected for variability in classroom size. Although it is possible that children with severe emotional and behavioral disorders react differently to peer acceptance and rejection (Little and Kobak 2003), Zakriski and Prinstein (2001) found that peer nominations were meaningful and related to social adaptation and psychological and behavioral adjustment in a clinical inpatient setting of children with significant emotional and behavioral problems.

\section{Data Analysis}

Autoregressive cross-lagged models were fitted in Mplus 6.12 (Muthén and Muthén 1998-2010). This software package allows the use of full information maximum likelihood (FIML) estimation to account for missing data. This FIML approach uses all information available in the data to estimate the individual log likelihood functions. Yet, only a small amount of data were missing. With regard to the STRS as rated by teachers, missing data ranged from 1 to $5 \%$ in each of the three assessment waves. With regard to peer nominations, missing data ranged from 4 to $7 \%$. We used maximum likelihood estimation with robust standard errors (MLR) as the estimator in our analyses because it is robust against nonnormality. We adjusted the standard errors of the estimated coefficients at the classroom level using the cluster-sampling 
module in Mplus in order to account for the hierarchical structure of the data, i.e., the dependencies among the observations (children) within clusters (classrooms). Fit of the theoretical models to the data was tested using the Comparative Fit Index (CFI), the Root Mean Squared Error of Approximation (RMSEA), and the Standardized Root Mean square Residual (SRMR). The fit of the models was considered adequate for a CFI above 0.95, a RMSEA below 0.06, and an SRMR below 0.08 (Hu and Bentler 1999).

Parameter estimates were controlled for study condition (intervention vs. control). For model parsimony, only the significant relations between study condition and the three outcome measures at each wave were retained in the model. Children's IQ was also considered for inclusion in the analyses, however, as there were no significant relations between children's IQ and the three outcomes measures, IQ was not included in our models.

To test our first hypothesis on the developmental links between disobedience and teacher-child and peer relationships, two separate models were fitted. The first model contained the positive dimensions of teacher-child and peer relationships, the second contained the negative dimensions (see Fig. 1). We started with fitting a baseline model (M1), which contained only autoregressive paths and cross-sectional correlations. The autoregressive part models the stability within each construct by regressing each variable on their immediate prior value. The cross-sectional part models the correlations between the three variables within one time point. Next, we tested the improvement of model fit over the baseline model when each of the six developmental links (model $2 \mathrm{a}$ : teacher to behavior; model $2 \mathrm{~b}$ : behavior to teacher; model 2c: peers to behavior; model 2d: behavior to peers; model 2e: teacher to peers; model $2 \mathrm{f}$ : peers to teacher) was subsequently added using the Satorra-Bentler scaled chi-square difference test (TRd; Satorra and Bentler 2001). We then estimated the final model (M3), which contained the links of the previous models (M2a-f) that showed superior model fit over M1. To test our second hypothesis regarding the impact of age, the total sample was split into a group of middle childhood boys (5-9 years old: $n=44 \%$ ) and a group of late childhood boys (10-13 years old: $n=56 \%$ ). We conducted multiple group modeling (younger vs. older boys) to test whether the strength of the developmental links were equal between age groups using Wald chi-square tests. To test our third hypothesis that developmental links are stronger between negative than positive social relationships and disobedience, we fitted two different models. Compared to Fig. 1, we now fitted one model containing the positive and negative dimensions of the teacher-child relationship (closeness vs. conflict) and disobedience, and a second model containing the positive and negative dimensions of peer relationships (acceptance vs. rejection) and disobedience. The positive social relationships
Fig. 1 Final autoregressive cross-lagged model of positive (upper part) and negative (lower part) social classroom relationships. Depicted values reflect standardized regression coefficients $(\beta)$. Only the significant developmental links are depicted. Cross-sectional correlations between the three constructs were also estimated but values are not depicted for readability

\section{Positive Social Classroom Relationships Model}

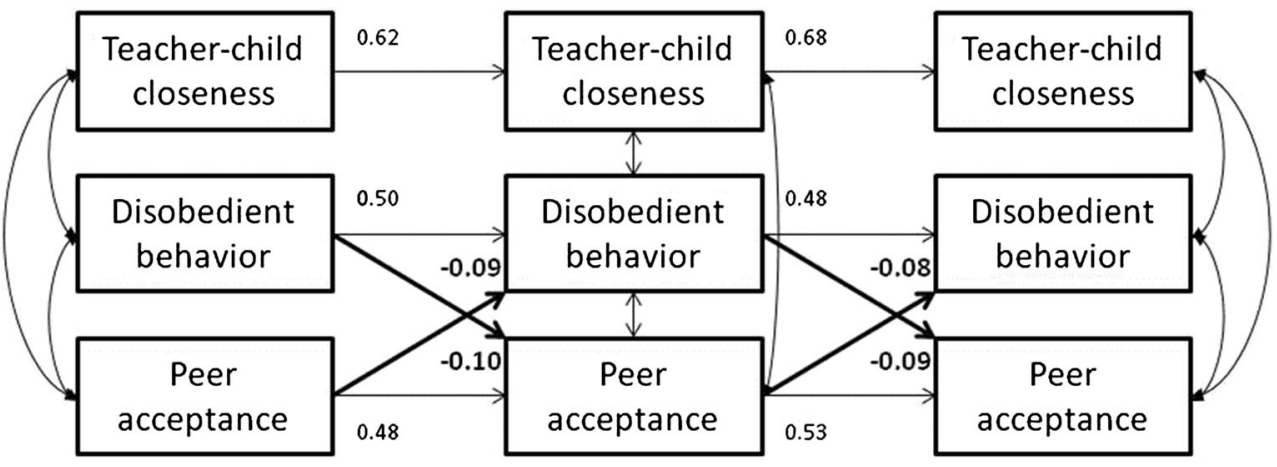

Negative Social Classroom Relationships Model

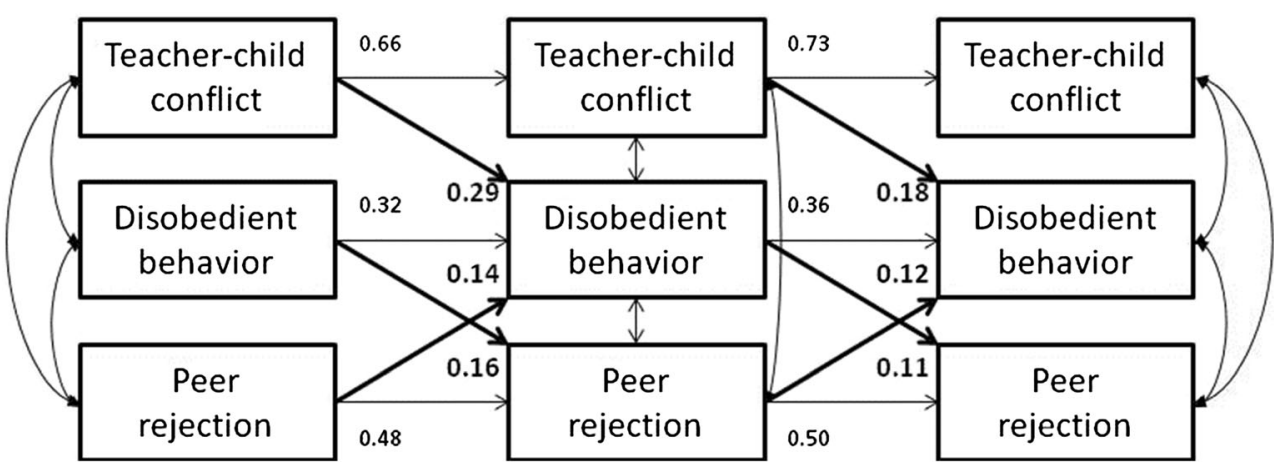


were reverse coded to test whether the strength of the developmental links between social relationships and disobedience were equal for positive and negative aspects of relationships.

\section{Results}

Disobedience and Positive and Negative Aspects of Teacher-Child and Peer Relationships

Means, standard deviations and correlations of disobedience, teacher-child and peer relationships are in Table 1. Table 2 reports on the fit statistics of the model fitting strategy. In the positive relationships model, model fit significantly improved only when developmental links were included from peer acceptance to disobedience (M2c) and from disobedience to peer acceptance (M2d). Therefore our final model (M3) consisted only of these four developmental links. All estimates are presented in Table 3. Lower levels of peer acceptance predicted increases in disobedience through the first half of the school year. In addition, higher levels of disobedience predicted decreases in boys' peer acceptance through the first half of the school year. As these results were not replicated in the second half of the school year, we tested whether links in the first and second half of the school year significantly differed. Results showed that model fit was not significantly reduced when the developmental links from $T_{1}$ to $T_{2}$ were constrained to be equal to the links from $T_{2}$ to $T_{3}$ (peers to behavior: $\operatorname{TRd}(1)=0.019, p=0.89$; behavior to peers: $\operatorname{TRd}(1)=1.829, p=0.18)$. With these time constraints, developmental links were significant between all waves. The upper part of Fig. 1 reports on the results of the positive relationships model with both these time constraints.

In the negative relationships model, model fit significantly improved compared to our baseline model when developmental links were included from teacher-child conflict to disobedience (M2a), from peer rejection to disobedience (M2c), from disobedience to peer rejection (M2d), and from teacher-child conflict to peer rejection (M2e; see Table 2). In Table 3 it can be seen that higher levels of teacher-child conflict predicted increases in disobedience but not vice versa. In addition, higher levels of peer rejection predicted increases in disobedience throughout the school year and higher levels of disobedience predicted increases in peer rejection throughout the school year. Although adding developmental links between teacher-child conflict and peer rejection improved model fit compared to our baseline model, these links were no longer significant above and beyond the six other developmental links in our final model. The results of our final model (M3) are depicted in Fig. 1 (lower part).

\section{The Impact of Age}

Next we examined whether the developmental links from teacher-child and peer relationships to disobedience differed for younger versus older boys. Wald test results showed that with regard to the model containing positive classroom relationships, only the link from disobedience in the beginning of the school year to peer acceptance halfway through the school year was stronger for older than for younger children (younger children: $B=-0.01$; older children: $B=-0.26$;

Table 1 Means, standard deviations and correlations of social relationships and disobedient behavior

\begin{tabular}{|c|c|c|c|c|c|c|c|c|c|c|c|c|c|c|c|c|}
\hline & $\mathrm{M}$ & SD & $1 \mathrm{~T}_{2}$ & $1 \mathrm{~T}_{3}$ & $2 \mathrm{~T}_{1}$ & $2 \mathrm{~T}_{2}$ & $2 \mathrm{~T}_{3}$ & $3 \mathrm{~T}_{1}$ & $3 \mathrm{~T}_{2}$ & $3 \mathrm{~T}_{3}$ & $4 \mathrm{~T}_{1}$ & $4 \mathrm{~T}_{2}$ & $4 \mathrm{~T}_{3}$ & $5 \mathrm{~T}_{1}$ & $5 \mathrm{~T}_{2}$ & $5 \mathrm{~T}_{3}$ \\
\hline $1 \mathrm{~T}_{1}$ & 3.76 & 0.66 & +0.63 & +0.58 & -0.37 & -0.26 & -0.17 & -0.26 & -0.22 & -0.08 & +0.01 & +0.07 & +0.08 & -0.13 & -0.12 & -0.16 \\
\hline $1 \mathrm{~T}_{2}$ & 3.72 & 0.68 & & +0.68 & -0.26 & -0.41 & -0.30 & -0.18 & -0.23 & -0.18 & +0.11 & +0.14 & +0.08 & -0.22 & -0.21 & -0.25 \\
\hline $1 \mathrm{~T}_{3}$ & 3.72 & 0.68 & & & -0.17 & -0.26 & -0.36 & -0.10 & -0.19 & -0.13 & +0.04 & +0.08 & +0.06 & -0.10 & -0.16 & -0.22 \\
\hline $2 \mathrm{~T}_{1}$ & 2.43 & 0.93 & & & & +0.65 & +0.57 & +0.47 & +0.48 & +0.36 & -0.03 & -0.12 & -0.11 & +0.24 & +0.24 & +0.21 \\
\hline $2 \mathrm{~T}_{2}$ & 2.57 & 0.93 & & & & & +0.73 & +0.34 & +0.51 & +0.39 & -0.05 & -0.15 & -0.10 & +0.17 & +0.23 & +0.26 \\
\hline $2 \mathrm{~T}_{3}$ & 2.51 & 0.94 & & & & & & +0.30 & +0.40 & +0.42 & -0.09 & -0.17 & -0.11 & +0.23 & +0.24 & +0.25 \\
\hline $3 \mathrm{~T}_{1}$ & 0.22 & 0.21 & & & & & & & +0.52 & +0.43 & -0.12 & -0.21 & -0.17 & +0.40 & +0.36 & +0.27 \\
\hline $3 \mathrm{~T}_{2}$ & 0.24 & 0.20 & & & & & & & & +0.49 & -0.16 & -0.36 & -0.23 & +0.33 & +0.45 & +0.37 \\
\hline $3 \mathrm{~T}_{3}$ & 0.29 & 0.24 & & & & & & & & & -0.16 & -0.23 & -0.22 & +0.29 & +0.33 & +0.41 \\
\hline $4 \mathrm{~T}_{1}$ & 0.37 & 0.20 & & & & & & & & & & +0.48 & +0.44 & -0.53 & -0.35 & -0.34 \\
\hline $4 \mathrm{~T}_{2}$ & 0.40 & 0.21 & & & & & & & & & & & +0.55 & -0.31 & -0.65 & -0.49 \\
\hline $4 \mathrm{~T}_{3}$ & 0.44 & 0.22 & & & & & & & & & & & & -0.30 & -0.44 & -0.68 \\
\hline $5 \mathrm{~T}_{1}$ & 0.22 & 0.18 & & & & & & & & & & & & & +0.52 & +0.42 \\
\hline $5 \mathrm{~T}_{2}$ & 0.24 & 0.19 & & & & & & & & & & & & & & +0.56 \\
\hline $5 \mathrm{~T}_{3}$ & 0.28 & 0.22 & & & & & & & & & & & & & & \\
\hline
\end{tabular}

$1=$ teacher-child closeness, $2=$ teacher-child conflict, $3=$ disobedient behavior, $4=$ peer acceptance, $5=$ peer rejection; significant correlations $(p<0.05)$ are depicted in bold 
Table 2 Fit statistics and model comparison of the positive and negative relationships models

\begin{tabular}{|c|c|c|c|c|c|c|c|c|c|c|c|}
\hline \multirow[t]{2}{*}{ Model } & \multicolumn{8}{|l|}{ Absolute fit } & \multicolumn{3}{|c|}{ Relative fit } \\
\hline & & $\chi^{2}$ & $d f$ & $\mathrm{scf}$ & CFI & RMSEA & SRMR & Comparison & $\mathrm{TRd}$ & $\Delta d f$ & $p$-value \\
\hline \multirow{8}{*}{$\begin{array}{l}\text { Positive relationships } \\
\text { model }^{\text {a }}\end{array}$} & M1: baseline model & 70.670 & 29 & 1.379 & 0.93 & 0.07 & 0.07 & & & & \\
\hline & M2a: teacher to behavior & 65.761 & 27 & 1.403 & 0.94 & 0.07 & 0.06 & Model 1-2a & 4.921 & 2 & 0.09 \\
\hline & M2b: behavior to teacher & 71.042 & 27 & 1.355 & 0.93 & 0.07 & 0.07 & Model 1-2b & 0.700 & 2 & 0.70 \\
\hline & M2c: peers to behavior & 64.886 & 27 & 1.407 & 0.94 & 0.06 & 0.06 & Model 1-2c & 6.153 & 2 & 0.05 \\
\hline & M2d: behavior to peers & 62.319 & 27 & 1.396 & 0.94 & 0.06 & 0.06 & Model 1-2d & 9.097 & 2 & 0.01 \\
\hline & M2e: teacher to peers & 68.821 & 27 & 1.404 & 0.93 & 0.07 & 0.07 & Model 1-2e & 0.796 & 2 & 0.67 \\
\hline & M2f: peers to teacher & 66.753 & 27 & 1.405 & 0.93 & 0.07 & 0.07 & Model 1-2f & 3.566 & 2 & 0.17 \\
\hline & M3: final model & 56.894 & 25 & 1.427 & 0.95 & 0.06 & 0.05 & Model 1-3 & 15.075 & 4 & $<0.01$ \\
\hline \multirow{8}{*}{$\begin{array}{l}\text { Negative relationships } \\
\text { model }^{\mathrm{b}}\end{array}$} & M1: baseline model & 98.032 & 28 & 1.317 & 0.91 & 0.09 & 0.11 & & & & \\
\hline & M2a: teacher to behavior & 65.512 & 26 & 1.344 & 0.95 & 0.07 & 0.09 & Model 1-2a & 42.505 & 2 & $<0.01$ \\
\hline & M2b: behavior to teacher & 96.769 & 26 & 1.306 & 0.91 & 0.09 & 0.11 & Model 1-2b & 1.868 & 2 & 0.39 \\
\hline & M2c: peers to behavior & 82.062 & 26 & 1.325 & 0.93 & 0.08 & 0.10 & Model 1-2c & 16.798 & 2 & $<0.01$ \\
\hline & M2d: behavior to peers & 78.053 & 26 & 1.345 & 0.94 & 0.08 & 0.09 & Model 1-2d & 25.317 & 2 & $<\mathbf{0 . 0 1}$ \\
\hline & M2e: teacher to peers & 91.892 & 26 & 1.344 & 0.92 & 0.09 & 0.10 & Model 1-2e & 5.803 & 2 & 0.05 \\
\hline & M2f: peers to teacher & 94.319 & 26 & 1.340 & 0.92 & 0.09 & 0.11 & Model 1-2f & 2.673 & 2 & 0.26 \\
\hline & M3: final model & 33.550 & 20 & 1.392 & 0.98 & 0.05 & 0.04 & Model 1-3 & 72.958 & 8 & $<0.01$ \\
\hline
\end{tabular}

$s c f$ scaling correction factor, $T R d$ Sattora-Bentler scaled chi-square difference, $\Delta d f$ difference in models' df

${ }^{a}$ the positive relationships model includes the significant pathway from study condition to peer acceptance at $\mathrm{T}_{1}$

${ }^{b}$ the negative relationships model includes the significant pathways from study condition to peer rejection at $T_{1}$ and $T_{2}$

$\left.\chi^{2}(1)=5.34, p=0.02\right)$. In the model containing negative classroom relationships, no age differences were found between older and younger children.

\section{Negative Versus Positive Social Relationships}

We examined the magnitude of the impact of positive versus negative social relationships on disobedience. To this end, two new models were fitted, one model for teacher-child closeness and conflict with disobedience, and a second model for peer rejection and acceptance with disobedience. Results showed stronger links for conflict than closeness to disobedience during the first half of the school year $\left(\mathrm{T}_{1}\right.$ conflict$\mathrm{T}_{2}$ behavior: $B=0.29, \mathrm{~T}_{1}$ closeness $-\mathrm{T}_{2}$ behavior: $B=0.01$, $\left.\chi^{2}(1)=5.43, p=0.02\right)$, but no significant difference between the impact of conflict and closeness was found during the second half of the school year $\left(\mathrm{T}_{2}\right.$ conflict $-\mathrm{T}_{3}$ behavior: $B=0.17, \mathrm{~T}_{2}$ closeness- $\mathrm{T}_{3}$ behavior: $B=0.02, \chi^{2}(1)=1.47$, $p=0.23$ ). Developmental links from disobedience to teacher-child conflict compared to closeness did not differ significantly in the first $\left(\mathrm{T}_{1}\right.$ behavior- $\mathrm{T}_{2}$ conflict: $B=0.05$, $\mathrm{T}_{1}$ behavior- $\mathrm{T}_{2}$ closeness: $\left.B=0.01, \chi^{2}(1)=0.50, p=0.48\right)$ and second half $\left(\mathrm{T}_{2}\right.$ behavior $-\mathrm{T}_{3}$ conflict: $B=0.03, \mathrm{~T}_{2}$ behavior$\mathrm{T}_{3}$ closeness: $\left.B=0.08, \chi^{2}(1)=0.18, p=0.68\right)$ of the school year. Results with regard to peer acceptance vs. rejection showed no stronger links of peer rejection than of acceptance to disobedience across the first $\left(\mathrm{T}_{1}\right.$ rejection- $\mathrm{T}_{2}$ behavior: $B=$ $0.14, \mathrm{~T}_{1}$ acceptance- $\mathrm{T}_{2}$ behavior: $B=0.04, \chi^{2}(1)=1.44, p=$ $0.23)$ and second half $\left(\mathrm{T}_{2}\right.$ rejection- $\mathrm{T}_{3}$ behavior: $B=0.15$, $\mathrm{T}_{2}$ acceptance- $\mathrm{T}_{3}$ behavior: $\left.B=-0.01, \chi^{2}(1)=1.76, p=0.19\right)$ of the school year. However, disobedience had a stronger link to rejection than to acceptance during the second half of the school year $\left(\mathrm{T}_{2}\right.$ behavior $-\mathrm{T}_{3}$ rejection: $B=0.14, \mathrm{~T}_{2}$ behavior$\mathrm{T}_{3}$ acceptance: $\left.B=0.00, \chi^{2}(1)=7.64, p<0.01\right)$, but not during the first half of the school year $\left(\mathrm{T}_{1}\right.$ behavior- $\mathrm{T}_{2}$ rejection: $B=$ $0.19, \mathrm{~T}_{1}$ behavior $-\mathrm{T}_{2}$ acceptance: $B=0.15, \chi^{2}(1)=0.33, p=0.57$ ).

\section{Discussion}

In this study, we set out to examine the developmental links between disobedience, teacher-child and peer relationships in a sample of boys with psychiatric disorders placed in segregated settings for special education followed across one school year. Our results confirm previous evidence supporting the importance of teacher-child conflict, but not closeness, and positive and negative peer relationships for the behavioral development of children, and extend these results to boys with psychiatric disorders in special education. However, contrary to our expectations, teacher-child and peer relationships were not longitudinally related, and the impact of boys' age on the developmental links was minimal. We did find support for a 
Table 3 Standardized and unstandardized estimates of the final models

\begin{tabular}{|c|c|c|c|c|c|c|}
\hline \multirow[t]{2}{*}{ Parameter } & \multicolumn{3}{|c|}{ Positive relationships model } & \multicolumn{3}{|c|}{ Negative relationships model } \\
\hline & $b$ & SE & $B$ & $b$ & SE & $B$ \\
\hline \multicolumn{7}{|l|}{ Autoregressive correlations } \\
\hline$T_{1}$ teacher to $T_{2}$ teacher & 0.63 & 0.06 & 0.62 & 0.66 & 0.05 & 0.66 \\
\hline$T_{2}$ teacher to $T_{3}$ teacher & 0.69 & 0.06 & 0.68 & 0.74 & 0.04 & 0.73 \\
\hline$T_{1}$ behavior to $T_{2}$ behavior & 0.50 & 0.07 & 0.51 & 0.32 & 0.06 & 0.32 \\
\hline$T_{2}$ behavior to $T_{3}$ behavior & 0.57 & 0.08 & 0.48 & 0.42 & 0.09 & 0.36 \\
\hline$T_{1}$ peers to $T_{2}$ peers & 0.49 & 0.06 & 0.47 & 0.50 & 0.06 & 0.48 \\
\hline$T_{2}$ peers to $T_{3}$ peers & 0.59 & 0.05 & 0.55 & 0.57 & 0.06 & 0.50 \\
\hline \multicolumn{7}{|l|}{ Cross-sectional correlations } \\
\hline $\mathrm{T}_{1}$ teacher with $\mathrm{T}_{1}$ behavior & -0.04 & 0.01 & -0.25 & 0.09 & 0.02 & 0.47 \\
\hline$T_{1}$ peers with $T_{1}$ behavior & -0.01 & 0.00 & -0.13 & 0.02 & 0.00 & 0.42 \\
\hline $\mathrm{T}_{1}$ teacher with $\mathrm{T}_{1}$ peers & 0.00 & 0.01 & 0.01 & 0.05 & 0.01 & 0.27 \\
\hline$T_{2}$ teacher with $T_{2}$ behavior & -0.01 & 0.01 & -0.13 & 0.04 & 0.01 & 0.33 \\
\hline$T_{2}$ peers with $T_{2}$ behavior & -0.01 & 0.00 & -0.29 & 0.01 & 0.00 & 0.30 \\
\hline$T_{2}$ teacher with $T_{2}$ peers & 0.01 & 0.01 & 0.12 & 0.02 & 0.01 & 0.13 \\
\hline $\mathrm{T}_{3}$ teacher with $\mathrm{T}_{3}$ behavior & 0.00 & 0.01 & 0.02 & $\mathbf{0 . 0 3}$ & 0.01 & 0.22 \\
\hline$T_{3}$ peers with $T_{3}$ behavior & -0.00 & 0.00 & -0.09 & 0.01 & 0.00 & 0.23 \\
\hline$T_{3}$ teacher with $T_{3}$ peers & 0.00 & 0.01 & 0.02 & 0.01 & 0.01 & 0.05 \\
\hline \multicolumn{7}{|l|}{ Developmental links ${ }^{\text {a }}$} \\
\hline$T_{1}$ teacher to $T_{2}$ behavior & - & - & - & 0.06 & 0.02 & 0.29 \\
\hline$T_{2}$ teacher to $T_{3}$ behavior & - & - & - & 0.05 & 0.02 & 0.18 \\
\hline$T_{1}$ behavior to $T_{2}$ teacher & - & - & - & - & - & - \\
\hline$T_{2}$ behavior to $T_{3}$ teacher & - & - & - & - & - & - \\
\hline$T_{1}$ peers to $T_{2}$ behavior & -0.10 & 0.06 & $-\mathbf{0 . 1 0}$ & 0.16 & 0.06 & 0.14 \\
\hline$T_{2}$ peers to $T_{3}$ behavior & -0.08 & 0.05 & -0.07 & 0.15 & 0.07 & 0.12 \\
\hline$T_{1}$ behavior to $T_{2}$ peers & -0.15 & 0.06 & -0.15 & 0.15 & 0.06 & 0.16 \\
\hline$T_{2}$ behavior to $T_{3}$ peers & -0.04 & 0.06 & -0.04 & 0.12 & 0.07 & 0.11 \\
\hline$T_{1}$ teacher to $T_{2}$ peers & - & - & - & 0.01 & 0.01 & 0.03 \\
\hline$T_{2}$ teacher to $T_{3}$ peers & - & - & - & 0.02 & 0.01 & 0.09 \\
\hline$T_{1}$ peers to $T_{2}$ teacher & - & - & - & - & - & - \\
\hline$T_{2}$ peers to $T_{3}$ teacher & - & - & - & - & - & - \\
\hline
\end{tabular}

a one-tailed test; $-=$ link not in the final model; significant estimates $(p<0.05)$ are depicted in bold

stronger effect of negative than positive relationships on disobedience.

\section{Developmental Links Between Disobedience and Social Relationships}

Our study does not show a consistent impact of the teacherchild relationship on boys' behavioral development, as an additive impact of conflict, not closeness, on later disobedience was found. This suggests that in special education, conflicts with teachers have a stronger longitudinal impact on classroom behavior than a close relationship with teachers. In line with studies in mainstream education (De Laet et al. 2014; Zhang and Sun 2011) we found that teacher-child conflict increased children's disobedience throughout the school year. On the other hand, our finding that a more positive teacher-child relationship didn't reduce boys' disobedience was not in line with some previous studies in mainstream education (Baker 2006; Hughes et al. 1999). However, the studies by Baker and Hughes et al. did not control for cross-sectional associations between teacher-child closeness and behavior problems and thereby possibly overestimated developmental effects. Studies in mainstream education that did conduct parallel assessments over time, and thereby controlled their outcomes for cross-sectional associations, actually showed mixed results. One study found higher teacherchild preference to decrease behavior problems (Mercer and DeRosier 2008), but others studies did not (Leflot et al. 2011; Zhang and Sun 2011). The difference between our and Mercer 
and DeRosier's findings might be explained by the younger age of their students making them more susceptible to teacher expectancies than the boys in our study (Kuklinski and Weinstein 2001). Another explanation for the lack of an additive impact of teacher-child closeness on boys' behavioral development in our sample, relates to the relatively high levels of social and behavioral problems of boys with psychiatric disorders in special education (Stoutjesdijk and Scholte 2009). These boys may have more difficulty in bonding with authority figures such as teachers, and may therefore be less susceptible to positive influences from teachers, a possibility which requires further research.

The teacher-child relationship does not seem affected by boys' disobedience as a reverse effect was not supported. This finding indicates that the teacher-child relationship - especially the negative component - is important for boys' future behavior, but that teachers' interactions with boys are not affected by their students' behavior problems in special education. This in line with some studies in mainstream education (Leflot et al. 2011; Zhang and Sun 2011), indicating that prior teacher-child closeness and concurrent behavior problems are stronger predictors of concurrent teacher-child closeness than prior behavior problems. However, opposite to our findings, some studies did find behavior problems to affect teacherchild conflict (De Laet et al. 2014; Doumen et al. 2008; Zhang and Sun 2011). As both the studies by Doumen et al. and Zhang and Sun also examined these developmental links within one school year, this suggests that in mainstream education, the teacher-child relationship seems affected by children's behavior problems, whereas in special education for children who all show some degree of behavioral problems, the teacher-child relationship seems less affected by such behavior. Thus, in mainstream education, behavior problems do present teachers with challenges that lead to conflict, but these challenges generally do not affect the teacherperceived closeness of the teacher-child relationship. An explanation as for why special education teachers appear not to be affected by boys' prior levels of behavior problems may be that special education teachers have specifically chosen, and undergone additional training, to work with children with severe levels of behavior problems. In addition, this finding suggests that special education teachers accept and treat their students irrespective of their behavior problems, which may be an important positive characteristic of special education as it contributes to creating a safe environment for vulnerable children.

With regard to peer relationships, we found support for developmental links between both positive and negative aspects of peer relationships and boys' behavioral development. Our findings show that peer acceptance reduces later disobedience, which in turn increases later peer acceptance. In addition, we found full transactional links between peer rejection and disobedience, indicating that prior disobedience evoked later rejection by peers, but once established, peer rejection had an additive effect on boys' development of disobedience, independent of prior disobedience. These results are consistent with results from studies in mainstream education (Leflot et al. 2011; Mercer and DeRosier 2008; Sturaro et al. 2011). The current study thereby extends prior research by signifying the importance of peers relationships for boys' behavioral development, for better and for worse, irrespective of boys' level of problematic behavior and educational setting.

\section{Developmental Links Between Teacher-Child and Peer Relationships}

In line with the study by Leflot et al. (2011), but in contrast to expectations based on social referencing theory (Hughes et al. 2001) and a number of other empirical studies in mainstream education (Chang et al. 2007; Hughes and Chen 2011; De Laet et al. 2014; Mercer and DeRosier 2008), we found that teacher-child conflict and closeness did not predict later increases in peer acceptance or rejection. However, in these previous studies, only concurrent teacher-child and peer relationships were assed (Hughes et al. 2001), estimates were not corrected for prior and concurrent teacher-child interactions (Chang et al. 2007), or not controlled for the impact of children's behavior (Hughes et al. 2001), which may all lead to overestimating developmental effects. Indeed, comparable to the results of Hughes and Chen, links between teacher-child conflict and peer rejection were significant when other developmental links were not included in our model. Our findings thus suggest that teachers are indeed the classroom authority who help shape norms and expectations with regard to peer interactional processes (Farmer et al. 2011), but that teachers' impact on peer relationships is less influential than the impact of children's disobedience. Note however that although the links between teacher-child conflict and peer rejection were not significant in our final model, the range of the standardized estimates of these links were in line with the significant estimates presented in the studies of Mercer and DeRosier and De Laet et al. In addition, in line with the findings of De Laet et al. (2014), but in contrast to other findings (Hughes and Chen 2011; Leflot et al. 2011; Mercer and DeRosier 2008), our study showed no support for the notion that peer relationships influence the teacher-child relationship over time. The difference between these and our findings may be explained by previously mentioned methodological issues. Also, in mainstream education, a decreased teacher preference for a child is explained by the lack of classroom participation as a result of peer rejection (Leflot et al. 2011). However, this may not apply to boys with special educational needs in selfcontained classrooms who show limited classroom participation from time to time, irrespective of the positivity or negativity of their peer relationships. 


\section{The Impact of Age}

In contrast to our expectations based on the findings by Kuklinski and Weinstein (2001) and Gifford-Smith and Brownell (2003), developmental links between disobedience and social relationships were largely similar for younger and older boys. Before the start of the study, we expected the teacher-child relationship to be more important for younger than older boys and peer relationships to be more important for older than younger boys, however we only found one developmental link supporting this hypothesis. It thus appears that age is not that important for the relationships among classroom processes in special education. This may be explained by the fact that for children with various psychiatric disorders in special education, their developmental level has a greater impact on their social and behavioral functioning than age. Because boys with psychiatric disorders who are similar in age may differ widely in their social and emotional development, their developmental level may thus overshadow true age effects. Therefore, in future studies in special education, it may be useful to assess both developmental level and age to test their impact on the links between behavior problems and social classroom relationships.

\section{Positive Versus Negative Social Experiences and Boys' Behavioral Development}

In line with our expectations, our study shows that teacherchild conflict has a greater impact on boys' disobedience than teacher-child closeness, confirming the theory of Baumeister et al. (2001) that individuals react more strongly to relational stressors than positive relational aspects. These relational stressors may produce strong negative emotions that may interfere with classroom participation and thus a child's sense of belonging (Ladd et al. 1999). With regard to peer relationships, our finding that disobedience has more impact on peer rejection than acceptance, whereas peer rejection and acceptance were equally important for boys' development of disobedience, indicates that both positive and negative peer relationships are important for boys' disobedience development, but that when boys show undesirable behavior, they may easily acquire a 'bad' reputation which is difficult to lose (Baumeister et al. 2001). The finding that negative social relationships more strongly impacted boys' classroom behavior than positive social relationships, is especially important for boys in special education, as these children not only already encounter more negative social interactions (Humphrey and Symes 2010; Little and Kobak 2003; Murray and Greenberg 2001), but also receive three times more punishment than children without social-emotional and behavioral disorders (Scott et al. 2011). It is thus vital to prevent the development of negative interactional patterns in special educational settings.

\section{Limitations}

This study has four main limitations that should be considered. The first limitation regards the generalizability of our findings. Because special education policies for children with psychiatric disorders and additional educational needs vary around the world, it is unclear to what extent our results can be generalized to children with psychological disabilities in special education in countries other than the Netherlands. Also, although drop-out was low (6\%) and our study had a high parental consent rate $(85 \%)$ the study's generalizability may be limited by selective non-participation. In addition, as data on ethnicity and SES were obtained with parent reports which had a relatively low response rate $(61 \%)$, the percentage of ethnic minority boys and boys with low SES may have been underestimated. Next, we focused only on boys in our study as few girls are placed in segregated settings for special education in the Netherlands. Whether our results also apply to girls in special education remains to be studied. Second, as many boys in our sample were diagnosed with ASD and therefore likely experience social difficulties because of their problems in perceiving and understanding social behavior (Bellini et al. 2007), and because self-perceptions of social status may impact the links between social relationships and behavior (Mayeux and Cillessen 2008), it is possible that the strength of these links differ for children with various diagnoses in special education settings. However, because many children in these settings have more than one diagnosis, including comorbid diagnoses of ASD and ADHD, and cope with complex psychiatric problems, it is difficult and possibly artificial to clearly categorize these children in specific subgroups. This study thus serves as a first important step in identifying the developmental links between behavior problems and social interactions in the classroom in children with complex social-emotional and behavioral difficulties in special education. The strength of the links between classroom relationships and behavior in children with specific psychiatric disorders remains to be studied in future research. Third, similar to the study by Zhang and Sun (2011), our results are limited to links during one school year. Developmental links within a school year may be stronger than links across two to three school years (e.g. Hughes and Chen 2011; De Laet et al. 2014; Leflot et al. 2011; Mercer and DeRosier 2008), as social relationships within a school year may remain more stable. To be able to better compare special to mainstream education, future research may want to examine links among classroom relationships and children's behavior across years in special education settings. Fourth, as both peer relationships and behavior problems were measured using peer nominations, 
the stronger developmental links between these constructs than between the teacher-child relationship and behavior problems, may be partly attributed to samesource bias. However, the fact that many classmates independently rated each child makes the peer nominations procedure less sensitive for same-source bias than single-rater procedures. In addition, we used multiple informants in this study who rated similar constructs in many mainstream education studies (i.e. peer-rated peer relationships, teacher-rated teacher-child relationship and peer-rated behavior problems; Hughes and Chen 2011; Leflot et al. 2011; Mercer and DeRosier 2008). Future research may want to examine these constructs using different informants or direct observations as this may yield a more complete understanding of classroom processes in special education.

\section{Conclusion and Practical Implications}

In summary, we found that despite differences in the severity of behavior problems between boys in mainstream and special education, the developmental links between disobedience and social relationships are quite similar across these two contexts: both teacher-child and peer relationships play an important role in the development of classroom behavior. With regard to peer relationships, it appears that boys with high levels of behavior problems elicit problematic relationships with peers, which exacerbates their already present problems. Being less preferred by classmates may thus be a stepping stone to a cascade of negative effects, thereby amplifying the risk faced by these already vulnerable children. Overall, our findings suggest that reducing negative interactional patterns may be more important than developing more positive interactional patterns in helping to prevent the development of problematic classroom behavior. As teacher-child conflict increased boys' disobedience, this basically implies that teachers should try to not fall into the trap of developing negative interactional patterns. Considering that most of these boys cope with social problems, it is important that special education teachers work on improving boys' social competence. In addition, in line with the findings of Gifford-Smith and Brownell (2003), teachers may also work on positively re-evaluating negative peer behavior in such a way that these boys experience their classmates as being helpful instead of hostile, to enhance boys' social and behavioral development and thereby making a difference for these vulnerable children.

Acknowledgments This work was supported by ZonMw, The Netherlands Organization for Health Research and Development (project number 15700.3011) and conducted by Yulius, the Erasmus MC-Sophia Children's Hospital, VU University Amsterdam, Utrecht University and the CED-group. We would like to thank all special education children and teachers for their participation in this study.
Conflict of Interest The authors declare that they have no conflict of interest.

\section{References}

Baker, J. A. (2006). Contributions of teacher-child relationships to positive school adjustment during elementary school. Journal of School Psychology, 44, 211-229.

Baumeister, R. F., Bratslavsky, E., Finkenauer, C., \& Vohs, K. D. (2001). Bad is stronger than good. Review of General Psychology, 5, 323-370.

Bellini, S., Peters, J. K., Benner, L., \& Hopf, A. (2007). A meta-analysis of school-based social skills interventions for children with autism spectrum disorders. Remedial and Special Education, 28, 153-162.

Bowlby, J. (1982). Attachment and loss: Vol. 1, attachment. (Original work published in, 1969). Harmondsworth: Penguin.

Breeman, L.D., Van Lier, P.A.C., Wubbels, T., Verhulst, F.C., Van der Ende, J., Maras, A., et al. Effects of the Dutch Good Behavior Game on the behavior, emotional and social problems of children with psychiatric disorders in special education settings. Manuscript Submitted for Publication.

Carrel, S. E., \& Hoekstra, M. L. (2010). Externalities in the classroom: how children exposed to domestic violence affect everyone's kids. American Economic Journal: Applied Economics, 2, 211-228.

Chang, L., Liu, H., Fung, K. Y., Wang, Y., Wen, Z., Li, H., et al. (2007). The mediating and moderating effects of teacher preference on the relations between students' social behaviors and peer acceptance. Merrill-Palmer Quarterly, 53, 603-630.

Coie, J. D., \& Dodge, K. A. (1988). Multiple sources of data on social behavior and social status in the school: a cross-age comparison. Child Development, 59, 815-829.

De Laet, S., Doumen, S., Vervoort, E., Colpin, H., Van Leeuwen, K., Goossens L., et al. (2014). Transactional links between teacher-child relationship quality and perceived versus sociometric popularity: a three-wave longitudinal study. Child Development, in press, advance online.

Diamantopoulou, S., Henricsson, L., \& Rydell, A. (2005). ADHD symptoms and peer relations of children in a community sample: examining associated problems, self-perceptions, and gender differences. International Journal of Behavioral Development, 29, 388-398.

Doumen, S., Verschueren, K., Buyse, E., Germeijs, V., \& Luyckx, K. (2008). Reciprocal relations between teacher-child conflict and aggressive behavior in kindergarten: a three-wave longitudinal study. Journal of Clinical Child \& Adolescent Psychology, $37,588-599$

Doumen, S., Verschueren, K., Buyse, E., De Munter, S., Max, K., \& Moens, L. (2009). Further examination of the convergent and discriminant validity of the student-teacher relationship scale. Infant and Child Development, 18, 502-520.

Farmer, T. W., McAuliffe Lines, M., \& Hamm, J. V. (2011). Revealing the invisible hand: the role of teachers in children's peer experiences. Journal of Applied Developmental Psychology, 32, 247-256.

Gifford-Smith, M. E., \& Brownell, C. A. (2003). Childhood peer relationships: social acceptance, friendships and peer networks. Journal of School Psychology, 41, 235-284.

Hamre, B. K., Pianta, R. C., Downer, J. T., \& Mashburn, A. J. (2008). Teachers' perceptions of conflict with young students: looking beyond problem behaviors. Social Development, 17, 115-136.

Heijmens Visser, J., Van der Ende, J., Koot, H. M., \& Verhulst, F. C. (2003). Predicting change in psychopathology in youth referred to mental health services in childhood or adolescence. Journal of Child Psychology and Psychiatry, 44, 509-519. 
Hinshaw, S. P., \& Melnick, S. M. (1995). Peer relationships in boys with attention-deficit hyperactivity disorder with and without comorbid aggression. Development and Psychopathology, 7, 627-647.

Hu, L., \& Bentler, P. M. (1999). Cutoff criteria for fit indexes in covariance structure analysis: conventional criteria versus new alternatives. Structural Equation Modeling: A Multidisciplinary Journal, 6, 1-55.

Hughes, J. N., \& Chen, Q. (2011). Reciprocal effects of student - teacher and student-peer relatedness: effects on academic self efficacy. Journal of Applied Developmental Psychology, 32, 278-287.

Hughes, J. N., Cavell, T. A., \& Jackson, T. (1999). Influence of the teacher-student relationship in childhood conduct problems: a prospective study. Journal of Clinical Child Psychology, 28, 173-184.

Hughes, J. N., Cavell, T. A., \& Willson, V. (2001). Further support for the developmental significance of the quality of the teacher - student relationship. Journal of School Psychology, 39, 289-301.

Humphrey, N., \& Symes, W. (2010). Perceptions of social support and experience of bullying among pupils with autistic spectrum disorders in mainstream education. European Journal of Special Needs Education, 25, 77-91.

Koomen, H. M. Y., Verschueren, K., \& Pianta, R. C. (2007). Student teacher relationship scale manual. [Leerling Leerkracht Relatie Vragenlijst. Handleiding]. Houten: Bohn Stafleu van Loghum.

Koomen, H. M. Y., Verschueren, K., Van Schooten, E., Jak, S., \& Pianta, R.C. (2012). Validating the Student-Teacher Relationship Scale: Testing factor structure and measurement invariance across child gender and age in a Dutch sample. Journal of School Psychology, 50, 215-234.

Kuklinski, M. R., \& Weinstein, R. S. (2001). Classroom and developmental differences in a path model of teacher expectancy effects. Child Development, 72, 1554-1578.

Ladd, G. W. (1990). Having friends, keeping friends, making friends, and being liked by peers in the classroom: predictors of children's early school adjustment? Child Development, 61, 1081-1100.

Ladd, G. W., Birch, S. H., \& Buhs, E. S. (1999). Children's social and scholastic lives in kindergarten: related spheres of influence? Child Development, 70, 1373-1400.

Leflot, G., Van Lier, P. A. C., Verschueren, K., Onghena, P., \& Colpin, H. (2011). Transactional associations among teacher support, peer social preference, and child externalizing behavior: a four-wave longitudinal study. Journal of Clinical Child \& Adolescent Psychology, 40, 87-99.

Little, M., \& Kobak, R. (2003). Emotional security with teachers and children's stress reactivity: a comparison of special-education and regular-education classrooms. Journal of Clinical Child and Adolescent Psychology, 32, 127-138.

Marks, P. E. L., Babcock, B., Cillessen, A. H. N., \& Crick, N. R. (2013). The effect of participation rate on the international reliability of peer nominations measures. Social Development, 22, 609-622.

Mayeux, L., \& Cillessen, H. N. (2008). It's not just being popular, it's knowing it, too: the role of self-perceptions of status in the associations between peer status and aggression. Social Development, 17, 871-887.

Meijer, C. J. W. (2003). Special education across Europe in 2003: Trends in provision in 18 European countries. Brussels: European Agency for Development in Special Needs Education.

Mercer, S. H., \& DeRosier, M. E. (2008). Teacher preference, peer rejection, and student aggression: a prospective study of transactional influence and independent contributions to emotional adjustment and grades. Journal of School Psychology, 46, 661-685.

Ministerie OCW. (2003). Regulation indication criteria pupil funding. No. $P O / L G F-2003 / 7110)$. Den Haag: author.
Murray, C., \& Greenberg, M. T. (2001). Relationships with teachers and bonds with school: social emotional adjustment correlates for children with and without disabilities. Psychology in the Schools, 38, $25-41$.

Muthén, L. K., \& Muthén, B. O. (1998). Mplus user's guide (6th ed.). Los Angeles: author.

Pianta, R.C. (2001). Student-teacher relationship scale: Professional manual. Psychological Assessment Resources, Inc.

Pianta, R.C., Hamre, B., \& Stuhlman, M. (2003). Relationships between teachers and children. In W. Reynolds and G. Miller (Eds.), Handbook of psychology: Vol. 7. Educational psychology, 199-234.

Rich, E. C., Loo, S. K., Yang, M., Dang, J., \& Smalley, S. L. (2009). Social functioning difficulties in ADHD: associations with PDD risk. Clinical Child Psychology and Psychiatry, 14, 329-344.

Russel, G., Golding, J., Norwich, B., Emond, A., Ford, T., \& Steer, C. (2012). Social and behavioural outcomes in children diagnosed with autism spectrum disorders: a longitudinal cohort study. Journal of Child Psychology and Psychiatry, 53, 735-744.

Sabol, T. J., \& Pianta, R. C. (2012). Recent trends in research on teacherchild relationships. Attachment and Human Development, 14, 213-231.

Satorra, A., \& Bentler, P. (2001). A scaled difference chi-square test statistic for moment structure analysis. Psychometrika, 66, 507-514.

Scott, T. M., Alter, P. J., \& Hirn, R. G. (2011). An examination of typical classroom context and instruction for students with and without behavioral disorders. Education and Treatment of Children, 34, 619-641.

Silver, R. B., Measelle, J. R., Armstrong, J. M., \& Essex, M. J. (2005). Trajectories of classroom externalizing behavior: contributions of child characteristics, family characteristics and the teacher-child relationship during the school transition. Journal of School Psychology, 43, 39-60.

Stoutjesdijk, R., \& Scholte, E. M. (2009). Special education for children with psychiatric problems: a comparison between students in separated schools for special education and students in inclusive education. [cluster 4 speciaal onderwijs: een vergelijking tussen leerlingen op cluster 4 scholen en cluster 4 rugzakleerlingen.]. Tijdschrift Voor Orthopedagogiek, 48, 161-169.

Sturaro, C., van Lier, P. A. C., Cuijpers, P., \& Koot, H. M. (2011). The role of peer relationships in the development of early school-age externalizing problems. Child Development, 82, 758-765.

Toste, J.R., Bloom, E.L., Heath, N.L. (2012). The differential role of classroom working alliance in predicting school-related outcomes for students with and without high-incidence disabilities. The Journal of Special Education, in press, advance online.

U.S. Department of Education. (2009). 31st annual report to congress on the implementation of the individuals with disabilities education act, 2009 (U.S. Department of Educationth ed.). Washington: author.

Verschueren, K., \& Koomen, H. M. Y. (2012). Teacher-child relationships from an attachment perspective. Attachment and Human Development, 14, 205-211.

Zakriski, A. L., \& Prinstein, M. J. (2001). Sociometric status of child inpatients in clinical and normative peer groups: is peer status in a clinical setting a useful measure of adjustment? Applied Developmental Psychology, 22, 157-173.

Zhang, X., \& Sun, J. (2011). The transactional links between teachers' perceptions of children's behavior problems and teacher-child relationships in the first preschool year. The Journal of Genetic Psychology, 172, 176-198. 